\title{
Extent of Electronic Prescribing Implementation as Perceived by MCO Pharmacy Managers
}

OBJECTIVE: To evaluate the extent of implementation of electronic prescribing by managed care organizations (MCOs) and to assess perceptions of implementation barriers.

DESIGN: In response to an electronic mailing, individuals in managerial pharmacy positions in MCOs completed a survey posted online.

\section{MAIN OUTCOMES MEASURED: The} number of responders in each of five stages of implementation of electronic prescribing was assessed. The stages included discussing, considering, developing, trialing, and evaluating electronic prescribing within the organization. A five-point rating scale was used to measure perception of barriers to implementing electronic prescribing, and the results were arrayed by geographic and other characteristics of each MCO.

RESULTS: Of the 260 subjects, 53 had undeliverable e-mail accounts, and 44 returned usable responses, resulting in a response rate of $21 \%$. The responses ranged from one from the Rockies to 17 from the Midwest. Among the 44 total respondents, 36
(82\%) had discussed implementing electronic prescribing, $11(25 \%)$ had developed a plan, but only seven (16\%) had actually implemented electronic prescribing. This distribution was observed regardless of MCO type or membership size or membership type. Provider resistance appeared to be rated as the highest barrier by those who considered implementation of electronic prescribing not feasible. In contrast, responders who had the opportunity to implement electronic prescribing appeared to rate the investment requirement as the highest barrier.

CONCLUSIONS: The extent of electronic prescribing implementation by MCOs might be minimal. Barriers to implementation may appear overwhelming at the early stages of discussion, but may change as the implementation process progresses.

KEYWORDS: Electronic prescribing, health plan implementation, managed care organizations, diffusion of innovation, point of care

J Managed Care Pharm 2002: 41-47

\section{by Diana Papshev and Andrew M. Peterson}

I $\mathrm{n}$ comparison to other record-dependent industries, health care has been using outdated and inefficient methods to store, retrieve, and transfer information. ${ }^{1-2}$ However, with advances in information technology (IT) in the 1990s, the health care industry increasingly relies upon computers. As we begin the 21st century, medical records, laboratory results, and prescriptions can be managed electronically. Use of electronic prescriptions has the potential to affect most components of the health care delivery system.

Recently, paperless prescribing, otherwise referred to as electronic prescribing or computerized physician order entry, has garnered much attention from physicians, pharmacists, managed care administrators, information technology managers, and entrepreneurs. ${ }^{2-8}$ The proliferation of application service providers (ASP) and hand-held technologies has accompanied electronic prescribing in the ambulatory care setting as information technology gains momentum. ${ }^{3}$

Ambulatory electronic prescribing promises a variety of benefits in the health care market. ${ }^{2-7}$ For instance, due to the potential to minimize medication errors, the Institute for Safe Medication Practices (ISMP), the National Coordinating Council for Medication Error Reporting and Prevention, the Academy of Managed Care Pharmacy, and the American Society of Health-System Pharmacists support the use of computerized order entry by prescribers. ${ }^{5,9-10}$ Electronic prescribing promises to enhance the efficiency and productivity of patient care. By decreasing data-entry and call volume in pharmacies and physician's offices, electronic prescribing could eliminate many time-consuming redundancies in the process of prescription ordering and recording. ${ }^{7}$ For managed care organizations (MCOs) and pharmacy benefit managers (PBMs), one of the most attractive features of electronic prescribing is the synchronization of point of care and point of service processes. Formulary status, prior authorization requirements, and drug utilization review (DUR) specifications can be directed at prescribers, not pharmacists, and at the point of prescribing, not dispensing. As demonstrated by several studies, automating formulary enforcement and prior authorization processes improves formulary compliance and generic substitution rates and lowers call center volume..$^{911-13}$ Electronic prescribing and more efficient transmission of information also has the potential to improve customer service and patient satisfaction by reducing pharmacy waiting time. ${ }^{14-15}$

Aside from the enthusiasm generated by the promise of electronic prescribing, data regarding the implementation of 


\begin{tabular}{l|l}
\hline TABLE 1) & $\begin{array}{l}\text { Diffusion of Innovation Theory Applied } \\
\text { to the Stages of Implementation of } \\
\text { Electronic Prescribing }\end{array}$ \\
\hline Diffusion of Innovation Stages & $\begin{array}{l}\text { Electronic Prescribing } \\
\text { Implementation Stages }\end{array}$ \\
\hline 1. Knowledge & $\begin{array}{l}\text { Awareness and discussion of } \\
\text { the technology }\end{array}$ \\
\hline 2. Persuasion & $\begin{array}{l}\text { Forming an attitude on } \\
\text { feasibility of implementation }\end{array}$ \\
\hline 3. Decision & $\begin{array}{l}\text { Development of an } \\
\text { implementation plan }\end{array}$ \\
\hline 4. Implementation & \begin{tabular}{l} 
Implementation tests \\
\hline 5. Confirmation
\end{tabular} \\
$\begin{array}{l}\text { Reinforcement based on } \\
\text { positive outcomes of } \\
\text { implementation tests }\end{array}$ \\
\hline
\end{tabular}

electronic prescribing in the ambulatory care setting are scarce. In the late 1990s the nation's largest PBMs, in partnership with various vendors, promoted the launch of electronic prescribing systems to their physicians. Except for fragments of information provided by a few press releases, no studies were published on the outcomes of these implementation efforts. In 2001, AdvancePCS, Express Scripts, and Merck-Medco formed the joint venture RxHub, in part, to facilitate implementation of electronic prescribing. The creation of RxHub served to lend some additional emphasis to the adoption of electronic prescribing and suggested continued interest in deploying this technology. While PBMs actively support adoption of computerized physician order entry in the ambulatory care environment, another crucial managed care player, MCOs, appear to be more reluctant. The uncertainty about MCO participation in the deployment of this technology spurred this preliminary crosssectional study to investigate the status of electronic prescribing implementation among MCOs in the United States.

According to Everett Rogers' diffusion of innovations theory (DOI), which has been applied to technological innovations in health care systems, organizations and other social systems progress through five stages of diffusion through which a new technology or innovation is adopted (Table 1) ${ }^{16-20}$ Wholey et a ${ }^{20}$ used the framework of DOI theory to gauge the degree of implementation of administrative and clinical information support systems within HMOs. In a telephone survey of 252 HMOs across the country, the investigators determined that while many HMOs have adopted information technology techniques for administrative purposes, they are only in the persuasion stage of using technology in clinical arenas.

The primary objective of this study was to evaluate the extent of implementation of electronic prescribing within MCOs. As in the Wholey study, we also used the DOI theory as a framework for developing a survey to determine the extent to which MCOs are implementing electronic prescribing (Table 1).

Perceptions of barriers to implementation were assessed as a secondary objective.

\section{Methods}

A survey comprised of 18 questions was developed (Find the complete survey online at www.amcp.org). The first four questions assessed geographic and organization-specific parameters, such as the type of managed care organization (staff HMO, group/network HMO, IPA HMO, mixed HMO, POS, PPO, mixed, or other), whether Medicaid lives were covered, and how many lives were covered.

The next series of questions addressed stages of electronic prescribing implementation. The survey inquired as to whether implementation of electronic prescribing had been discussed within the organization, if it was considered to be feasible, whether an implementation plan had been developed, and if the plan had been implemented and/or evaluated.

Through a literature review, six barriers to implementation of electronic prescribing were identified: (1) insufficient knowledge of the concept, (2) requirement of a considerable investment, (3) lack of technology standardization, (4) segmentation of the health care market, (5) provider resistance, and (6) regulatory restrictions/indecisiveness. ${ }^{2,5,21} \mathrm{~A}$ rating scale was provided so that the respondents could rate their perception of barriers that would be encountered or were actually encountered in the process of implementing electronic prescribing. The barriers were rated on the scale of 1 to 5 ( $1=$ not a barrier, $2=$ barrier easily overcome, 3 = barrier overcome with some effort, $4=$ barrier overcome with great effort, $5=$ insurmountable barrier). An open-ended question also allowed respondents to list barriers other than the ones listed.

Where an implementation plan was developed, respondents were asked to identify from a list (Table 2 , this page) or to provide on their own, which electronic prescribing vendor(s) had been

\section{TABLE 2 List of E-Prescribing Vendors/Products Provided in Survey}

- Allscripts (Touchscript)

- Abaton.com (Clinical Suite)

- AHT (@Rx)

- Axolotl (Prescription Writer)

- Data Critical (Web Chart/Pocket Chart)

- DocPlanet.com (DocScript)

- ePhysician (ePad, eDR)

- Firekey (n-Suite)

- Heleos (myHippo)
- iMedica (iMedica PhysicianSuite)

- iScribe (i3000/i5000)

- InfoScriber (InfoScriber)

- LogonHealth (ePrescription Center)

- MDPad (MDPad)

- Med-I-Nets.com

- ParkStone (PPARIS System)

- Rx-Pro.com (Rx-Pro Palm VII)

- WirelessMD (WirelessMD) 
Extent of Electronic Prescribing Implementation as Perceived by MCO Pharmacy Managers

\section{TABLE 3 Stages of Implementation of Electronic Prescribing According to Geographic or Organizational Characteristics}

\begin{tabular}{|c|c|c|c|c|c|c|}
\hline \multirow[t]{2}{*}{ Characteristic } & & \multicolumn{5}{|c|}{ Number of Respondents } \\
\hline & & $\begin{array}{c}\text { Total } \\
(\mathrm{n}=44)\end{array}$ & $\begin{array}{c}\text { Discussed } \\
(\mathrm{n}=36)\end{array}$ & $\begin{array}{l}\text { Deemed } \\
\text { Feasible } \\
(\mathrm{n}=27)\end{array}$ & $\begin{array}{l}\text { Developed Plan } \\
\quad(\mathrm{n}=11)\end{array}$ & $\begin{array}{l}\text { Implemented } \\
\quad(\mathrm{n}=7)\end{array}$ \\
\hline Region & $\begin{array}{l}\text { Midwest } \\
\text { Northeast } \\
\text { Mid-Atlantic } \\
\text { West } \\
\text { Southeast } \\
\text { Southwest } \\
\text { Rockies-Plains }\end{array}$ & $\begin{array}{l}17 \\
7 \\
6 \\
6 \\
4 \\
3 \\
1\end{array}$ & $\begin{array}{l}13 \\
6 \\
6 \\
6 \\
2 \\
3 \\
0\end{array}$ & $\begin{array}{l}11 \\
5 \\
5 \\
5 \\
0 \\
1 \\
0\end{array}$ & $\begin{array}{l}4 \\
5 \\
0 \\
2 \\
0 \\
0 \\
0\end{array}$ & $\begin{array}{l}3 \\
3 \\
0 \\
1 \\
0 \\
0 \\
0\end{array}$ \\
\hline MCO type & $\begin{array}{l}\text { HMO } \\
\text { Mixed } \\
\text { Other } \\
\text { PPO }\end{array}$ & $\begin{array}{c}27 \\
10 \\
6 \\
1\end{array}$ & $\begin{array}{c}20 \\
10 \\
5 \\
1\end{array}$ & $\begin{array}{c}17 \\
6 \\
3 \\
1\end{array}$ & $\begin{array}{l}6 \\
4 \\
1 \\
0\end{array}$ & $\begin{array}{l}4 \\
3 \\
0 \\
0\end{array}$ \\
\hline Number of covered lives & $\begin{array}{l}<100,000 \\
100,000-300,000 \\
300,001-500,000 \\
500,001-1,000,000 \\
>1,000,000\end{array}$ & $\begin{array}{c}6 \\
16 \\
11 \\
2 \\
9\end{array}$ & $\begin{array}{c}5 \\
11 \\
10 \\
1 \\
9\end{array}$ & $\begin{array}{l}3 \\
9 \\
8 \\
1 \\
6\end{array}$ & $\begin{array}{l}1 \\
3 \\
4 \\
1 \\
2\end{array}$ & $\begin{array}{l}0 \\
3 \\
2 \\
1 \\
1\end{array}$ \\
\hline Medicaid coverage & $\begin{array}{l}\text { Yes } \\
\text { No }\end{array}$ & $\begin{array}{l}23 \\
21\end{array}$ & $\begin{array}{l}18 \\
18\end{array}$ & $\begin{array}{l}14 \\
13\end{array}$ & $\begin{array}{l}6 \\
5\end{array}$ & $\begin{array}{l}3 \\
4\end{array}$ \\
\hline
\end{tabular}

MCO - managed care organization, HMO - health maintenance organization, $P P O$ - preferred provider organization

considered, implemented and/or evaluated. In cases where an implementation plan had been developed, respondents also were asked to select the preferred charge model negotiated or to be negotiated between the MCO and an electronic prescribing vendor. If implementation had been carried out, the survey inquired about the number of prescribers enrolled. Finally, those who had the opportunity to evaluate the results of implementation were surveyed about their organizations' attitudes towards electronic prescribing technology.

The 2000-2001 edition of the Academy of Managed Care Pharmacy (AMCP) membership directory was used to select a sampling frame, which included individuals occupying managerial pharmacy positions in MCOs throughout the United States. It was thought that vice presidents, directors, supervisors, or managers of pharmacy services would likely be involved in electronic prescribing initiatives. Two hundred sixty potential participants with available e-mail addresses were identified. The greatest proportion of potential participants was from the Midwest (29.2\%), with the six other regions each contributing less than $15 \%$ of the sample.

An online survey management firm (www.Zoomerang.com) was used to post the questions on a Web site. Subjects were emailed a cover letter with a hyperlink to the survey. No instructions were given to forward the survey to someone else should the recipient feel unqualified to answer the questions. Before the survey was distributed, two individuals representing the target audience (MCO pharmacy managers) were asked to complete the survey and provide feedback on the content and accessibility. No changes were recommended. Two e-mailings were conducted during the one-month period of February 14 to March 14, 2001. The survey management firm recorded the responses in a database. The results were imported into Microsoft Excel and analyzed using descriptive statistics. A Chi Square test was used to compare geographic distribution of the respondents with that of the originally selected sample.

\section{Results}

From 260 selected e-mail accounts, 53 were excluded as undeliverable. Usable responses were obtained from 44 individuals, resulting in a response rate of $21 \%$ of the valid e-mail addresses. Geographic and organizational characteristics of MCOs represented by the respondents are summarized in Table 3. The 


\section{FIGURE 1 Stages of Implementation of} Electronic Prescribing

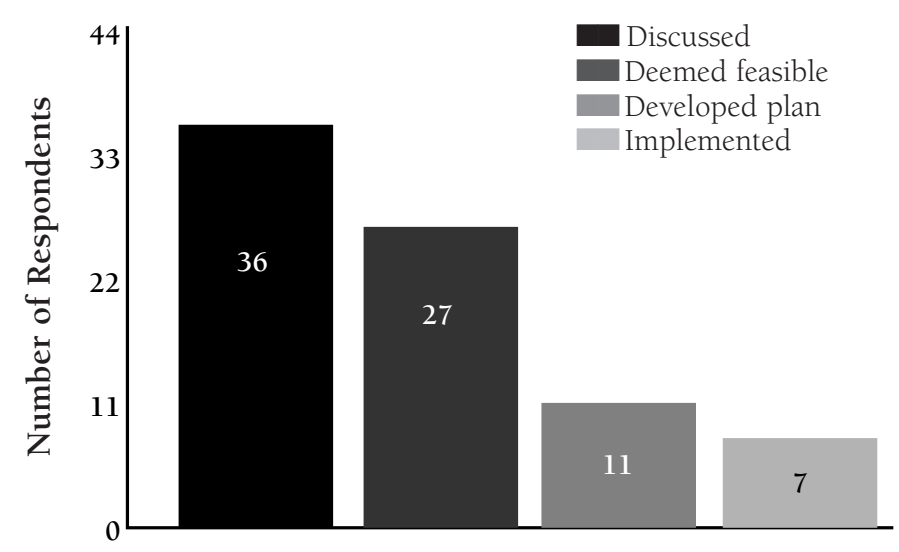

\section{TABLE 4 Respondents' Perception of Barriers to Implementing Electronic Prescribing}

\begin{tabular}{|c|c|c|}
\hline \multirow{2}{*}{$\begin{array}{l}\text { Barrier } \\
\text { Implementation }\end{array}$} & \multicolumn{2}{|c|}{ Mean Rating Score } \\
\hline & $\begin{array}{l}\text { Not feasible } \\
\quad(\mathrm{n}=9)\end{array}$ & $\begin{array}{c}\text { Implementation } \\
(\mathrm{n}=7)\end{array}$ \\
\hline $\begin{array}{l}\text { Insufficient knowledge } \\
\text { of the concept }\end{array}$ & 2.78 & 2.71 \\
\hline $\begin{array}{l}\text { Requirement of a considerable } \\
\text { investment }\end{array}$ & 3.22 & 3.43 \\
\hline $\begin{array}{l}\text { Lack of technology } \\
\text { standardization }\end{array}$ & 3.78 & 2.57 \\
\hline $\begin{array}{l}\text { Segmentation of the health care } \\
\text { market }\end{array}$ & 3.56 & 3 \\
\hline Providers' resistance & 3.89 & 3 \\
\hline $\begin{array}{l}\text { Regulatory restrictions/ } \\
\text { indecisiveness }\end{array}$ & 3.56 & 2 \\
\hline
\end{tabular}

Rating key: 1 = not a barrier, 2 = barrier easily overcome, 3 = barrier overcome with some effort, $4=$ barrier overcome with great effort, $5=$ insurmountable barrier

respondents' geographical distribution was similar to that of the original sample $\left(\chi^{2}=1.9, \mathrm{p}=0.39\right)$. An HMO was the most common type of MCO represented. Nearly half of the MCOs covered more than 300,000 lives, including Medicaid lives.

The extent of implementation of electronic prescribing is depicted in Figure 1. While 82\% percent (36/44) of respondents discussed the technology within their organizations, only $16 \%(7 / 44)$ had carried it through to implementation. Even fewer (just four of 44 respondents) had evaluated their implementation efforts. No differences in implementation trends were noted by region, MCO type, number of covered lives, or Medi- caid coverage. No statistical tests were performed due to the small number of respondents in each category. Explanations provided for the lack of discussion of implementing electronic prescribing within an organization included regulatory constraints, use of electronic medical records with a built-in formulary, and heavy reliance on paper billing by physicians.

Of 27 organizations that considered implementation feasible, only 11 selected or considered at least one electronic prescribing vendor for a developed plan. Ten vendors were chosen or considered for implementation plans. Products by Allscripts, Abaton, MDPad, iScribe, ePocrates, and MedicaLogic were implemented; only those by Allscripts, MDPad, and ePocrates were actually evaluated after implementation.

Seven of 44 (16\%) organizations surveyed reported having implemented at least one electronic prescribing product. Within any organization, the most prescribers using electronic prescribing was 200, with almost half the organizations using fewer than 25 prescribers. As a result of evaluating the implementation trials, two respondents were willing to expand the number of prescribers while two wanted to test other vendors.

There was no consensus among organizations with a developed implementation plan regarding preferences for a vendor charge method. Only two of 11 organizations favored a transaction-based method. Some organizations preferred member- or provider-based charge methods, while others planned to rely on the PBM sponsorship or to purchase hardware and software. None of the respondents selected a fee-based charge method.

Respondents were asked to rate six implementation barriers to electronic prescribing. A mean score for each barrier was calcualted. Respondents were segregated into those who considered implementation infeasible ( 9 respondents) and those who had implemented the technology (7 respondents). Table 4 compares mean rating scores between these two groups.

\section{Discussion}

The DOI theory as originally described by Everett Rogers offers a social framework for explaining the process of change. ${ }^{16}$ In particular, the DOI theory suggests that diffusion of innovations (new ideas, practices, or objects) occurs through certain communication channels among members of a social system. The process of adopting an innovation by members of the social system undergoes a series of stages. These stages occur in specific order and are time-dependent. The first stage, knowledge of the innovation, occurs when members of the social system first learn about the innovation. The second stage, persuasion, occurs when the members form an opinion regarding the feasibilitiy of adopting the innovation. The decision stage is where members take active steps to accept or reject the innovation. At this stage, the decision to try to innovate is usually made. This stage is followed by the implementation stage where the social system uses the innovation on a regular basis. Lastly, the members of the social system undergo a confirmation stage where the decision to adopt 
the innovation is reinforced, or reversed if the innovation is counter-productive. It is at this stage that benefits of the innovation are recognized and fully integrated into the ongoing routine of the social system, if appropriate. At each stage in the process of change, an increasing percentage of the members of the social system adopt the innovation, unless a barrier or conflict arises that slows, or halts, the adoption process.

Table 1 shows the relationship of the stages of DOI to the electronic prescribing implementation stages. The results of this small survey suggest that the surveyed MCOs are in the early stages of diffusion. The majority of these MCOs are approaching the stage of persuasion, where a decision on the feasibility of implementation must be made, and only a few have developed an implementation plan. The small sample size precluded further categorization of MCOs by stage of adoption.

Elson stated in the Journal of Managed Care Pharmacy last year that managed care pharmacy "either needs to hop on board or jump out of the way" of the electronic prescribing train that "has left the station and is picking up steam." ${ }^{\text {"3 }}$ Our sampling showed that many managed care pharmacy managers are contemplating "hopping on board" (61\% deemed implementation feasible) but few are actually on the electronic prescribing "train" (16\% implemented). While the Institute of Medicine report on medical errors and the wide publicity of the benefits of electronic prescribing ${ }^{2-6}$ has increased awareness of the potential value of electronic prescribing, less attention has been devoted to the implementation barriers and the reasons so few MCOs have attempted implementation. This study suggests that significant barriers do exist to the implementation of electronic prescribing and they are present regardless of the location, type and size of the MCO.

In order to eliminate handwritten prescriptions by 2003 , as called for by the ISMP, considerable financial resources are required for hardware, software, and service expenses. ${ }^{10}$ Electronic prescribing product vendors are looking into several sources of revenue, including MCOs/PBMs, retail pharmacies, prescribers, and pharmaceutical companies. Most of the revenue generators involve the imposition of subscription or transaction fees. A more detailed discussion of revenue models is available elsewhere. ${ }^{8}$ The following market estimates were projected in the W.R. Hambrecht report in 2000, specifically for hand-held devices:

- Physicians: up to $\$ 100$ per month (might include e-labs)

- PBMs/MCOs: $\$ 0.65$ - \$1.50 per transaction

- Retail pharmacies: \$0.25 per transaction

- Pharmaceutical companies (collectively as a market by 2004): a significant share of up to $\$ 300$ million

At a transaction fee of $\$ 1.00$, a managed care plan processing eight electronic transactions monthly for each of its 120,000 members would incur nearly $\$ 12$ million in annual transaction fees. Therefore, if transaction-based charge models are widely accepted, PBMs and MCOs might become the most significant revenue contributors. In addition, many electronic prescribing vendors are likely to seek active participation of both MCOs and PBMs in implementing their products due to the need for access to pharmacy claims and to customized, continually evolving formularies, DUR edits, and prior authorization requirements. It is interesting to note that a very small number of organizations that developed a plan for implementing electronic prescribing (two of 11 respondents) favored a transaction-based charge method, possibly because paying for every transaction can result in a large monthly charge. For instance, with the use of electronic prescribing in health plans with a closed formulary and mandatory generic substitution might produce cost savings on only a limited number of transactions (e.g., claims requiring prior authorization, claims eligible for DUR edits, etc.) and yet would be forced to distribute their charges to every transaction processed..$^{22}$

The perception of barriers might be the greatest limiting factor to implementing any technology. Implementation would not even be considered if barriers were perceived to be insurmountable. On the other hand, if initial implementation attempts failed because some barriers were underestimated or not even considered, further deployment would be halted. To implement electronic prescribing, the health care industry faces some of the same barriers it encountered with the adoption of point-of-service claims processing and electronic patient records. ${ }^{1,2,23-26}$ The requirement of capital, limitations set by legislators, providers, and segmented/fragmented technology and health care markets are some of the barriers already confronting the electronic prescribing industry.

Though statistical tests were not performed, provider resistance seemed to be rated as the highest barrier by those who considered implementation of electronic prescribing infeasible, with its mean rating score corresponding to a perception of a barrier overcome only with great difficulty. In contrast, respondents who had the opportunity to implement electronic prescribing rated "considerable investment requirement" as the highest barrier, which corresponded to a barrier that had been overcome with some effort. Respondents who were pessimistic about implementing electronic prescribing tended to assign higher barrier rating scores, with the exception of financial requirements. The greatest disparities in ratings between both groups were observed for technology, provider, and regulatory barriers. A possible explanation of these disparities is that most of the implementation trials assessed by this survey were on a relatively small scale, and these barriers were not as noticeable. In addition, initial implementation trials are usually voluntary, and provider resistance would not be expected to be a significant factor in voluntary trials of new technology. However, wide-scale deployment of electronic prescribing would be likely to encounter provider resistance.

Several studies have evaluated prescriber attitudes toward electronic medical records, which are closely correlated with electronic prescribing. . $^{27-31}$ Training requirements, interfering with workflow, computer anxiety, limited computer experience, and 
suspicion of over-regimentation and regulation of care were cited as the most likely reasons underlying prescriber resistance or reluctance to change. A lesser rating of provider resistance by those respondents who were more optimistic about implementing electronic prescribing may have several reasons and implications. It is possible that the optimistic organizations considered provider factors when selecting and evaluating electronic prescribing product vendors before implementation trials. Another implication of this finding could be that, through the course of implementation, provider resistance decreased.

Although respondents attempting to implement electronic prescribing technology tended to assign lower barrier ratings, their perception of funding as a barrier was greater than those who thought that implementation was infeasible, probably reflecting their acute knowledge of the subject. Before implementation is initiated, funding requirements are likely to be underestimated. Financial investment remains a deployment obstacle partly because limited data are available on consistent long-term positive return on investment. However, it has been speculated that rapid technology evolution may lower start-up costs of electronic medical records and thus electronic prescribing. ${ }^{32}$

\section{Limitations}

This study had a number of limitations. Members with executive-level titles were selected because it was assumed that people in these positions would most likely be involved in discussions and implementation of electronic prescribing. It is possible, however, that initiatives could have been taken without the respondents' awareness. No attempt was made to prequalify their actual involvement in consideration, adoption or implementation of e-prescribing technology.

Although posting a survey through an online survey manager minimized distribution cost and decreased response time, it introduced several limitations. Since e-mail was used as the contact method, potential respondents who did not have e-mail address listed in the AMCP membership directory were not reached. Furthermore, those who relied on the AMCP-listed e-mail accounts on a daily basis were probably more likely to answer the survey. These individuals may represent a segment of the AMCP membership who have more experience using technology tools and may be more knowledgeable about electronic prescribing, potentially biasing the responses. Individuals also often report their own perceptions and so the individual responses may not accurately represent the experiences of the organizations as a whole.

The low response rate of $21 \%$ resulted in a small sample size of 44 respondents. This is not unexpected since only two e-mail contacts were made during the study period, compared to the method employed by Wholey, ${ }^{20}$ which involved multiple followup telephone calls to HMOs, resulting in a $43 \%$ response rate. Unfortunately, this "minority sample" may under- or over-represent interest in and planned adoption and implementation of e- prescribing technology.

Also, we did not attempt to determine the construct validity of the questionnaire, and we only used two individuals to field test the survey instrument. To minimize the time needed to complete the survey, we did not provide any definitions within the text and left several terms and instructions up to the interpretation of the participants. Since formal definitions of electronic prescribing or barriers were not provided, some questions might have had different meanings for different respondents. For example, the regulatory barrier (listed as "regulatory restrictions/indecisiveness" in the survey) was not defined and could have been interpreted as two distinct components, or as a compound item. Respondents could have assumed this item referred to the limitations imposed by current regulations, the indecisiveness due to the lack of regulations, or a compound item consisting of both interpretations.

\section{Conclusions}

The data gathered by this study suggest that although many surveyed organizations are aware of electronic prescribing, the extent of the implementation of this technology by managed care organizations is minimal. Geographic and organizational characteristics did not appear to influence the extent of implementation. Barriers to implementation may appear overwhelming at the early stages of discussion, resulting in pessimistic attitudes toward the technology. The perception of these barriers, with the exception of capital requirements, may diminish as the implementation process progresses, though the reliability of this conclusion is questionable. In addition, this small, self-selected sample makes it difficult to extrapolate the results to the entire $\mathrm{MCO}$ industry.

Nevertheless, this study provides a platform for further, more substantial investigations and evaluation of the application of diffusion-adoption theories to electronic prescribing. Future research might also address privacy concerns, medication errors, quality improvement and provider adoption rates. Additional research that monitors the implementation of electronic prescribing on a larger scale should be performed. Further investigations into the nature of implementation barriers may be able to identify potential solutions.

Editor's Note: This sample of AMCP members with e-mail addresses probably over-represents interest in and planned adoption-implementation of e-prescribing technology. The response rate of 21 percent makes plausible almost any alternate explanation of the survey results. Nevertheless, this study provides a platform for further, more substantive investigation and evaluation of the application of theories of diffusion-adoption to the important subject of IT solutions to medication errors and quality improvement in patient service. Future research might also address the still-swirling controversy over patient privacy concerns versus health care quality improvement. The subject of the cost-effectiveness of e-prescribing and barriers to adoption 


\section{Extent of Electronic Prescribing Implementation as Perceived by MCO Pharmacy Managers}

and implementation is ripe for further cultivation by other researchers.

\section{Disclosures}

Diana Papshev is the principal author of this paper. Study concept and design, analysis and interpretation of data, drafting and critical revision of the paper all were conducted by Papshev and Andrew Peterson. Peterson was also responsible for statistical analysis. Funding support was provided by the Philadelphia College of Pharmacy/University of the Sciences in Philadelphia. Technical support was donated by Zoomerang.com.

\section{References}

1. Reilly F. Benefits and barriers to automated medical records. Testimony before the Committee on Government Affairs, U.S. Senate. 1994.

2. Academy of Managed Care Pharmacy. The electronic prescription record [Online]. Available: www.amcp.org/public/pubs/concepts/electronic.html [September 2000].

3. Elson B. Electronic prescribing in ambulatory care: a market primer and implications for managed care pharmacy. J Managed Care Pharm 2001; 7: $115-20$.

4. Pankaskie M, Sullivan J. New players, new services: e-scripts revisited. J Am Pharm Assoc 2000; 40: 566

5. Ukens C. Are you ready? Drug Topics 2000; 144: 34-39.

6. National Association of Chain Drug Stores. Electronic prescribing and the pharmacy. NACDS Chain Pharmacist Practice Memo 2000; 4: 1-3.

7. Strongin RJ. Physician connectivity: electronic prescribing. Issue Brief, Natl Health Policy Forum 2000; 752: 1-6.

8. Fisher J, Wang R. The cure is in hand: bringing information technology to patient care. WR Hambrecht and Co. [Online]. Available:

www.wrhambrecht.com/research/coverage/ehealth/ir/ir20001019.pdf [November 2000].

9. Poikonen J, Levelthal JM. Medication-management issues at the point of care. J Healthcare Info Mgmt [Online] 1999. Available from: www.himss.org/members/secure/journal/13-2/13205.html [September 2000].

10. The Institute for Safe Medication Practices. A call to action: eliminate handwritten prescriptions within three years [Online]. Available: www.ismp.org/MSAarticles/Whitepaperl.html [September 2000]

11. Farrar KT, Slee AL, Hughes DK. Formulary management by physician order entry systems, fact or fiction [abstract]. Proceedings ASHP Midyear 1996.
12. Rivkin S. Opportunities and challenges of electronic physician prescribing technology. Med Interface 1997; 10: 77-80, 83

13. Kielty M. Improving the prior authorization process to the satisfaction of customers. Am J Health Syst Pharm 1999; 56: 1499-1501.

14. Briesacher B, Corey R. Patient satisfaction with pharmaceutical services at independent and chain pharmacies. Am J Health Syst Pharm 1997; 54: 53136

15. Johnson KA, Parker JP, McCombs JS, Cody M. The Kaiser

Permanente/USC patient consultation study: patient satisfaction with pharmaceutical services. Am J Health Syst Pharm 1998; 55: 2621-2629.

16. Rogers EM. Diffusion of innovations, 4th ed. New York: Free Press, 1995.

17. Schubart JR, Einbinder JS. Evaluation of a data warehouse in an academic health sciences center, Proceedings AMIA Symposium 1999; 614-18.

18. Ash J. Factors affecting the diffusion of the computer-based patient record, Proceedings AMIA Symposium 1997; 682-86.

19. Ashry NY, Taylor WA. Requirements analysis as innovation diffusion: a proposed requirements analysis strategy for the development of an integrated hospital information support system, Proceedings HICSS Symposium 2000.

20. Wholey DR, Padman R, Hamer R, Schwartz S, The diffusion of information technology among health maintenance organizations. Health Care Mgmt Rev 2000; 25: 24-33.

21. Papshev D, Peterson AM. Electronic prescribing in ambulatory practice: promises, pitfalls, and potential solutions. Am J Manag Care 2001; 7: 725736.

22. Papshev D, Peterson AM. Rationalizing implementation of electronic prescribing in ambulatory practice: Medicaid plan case report. Proceedings PSHP Midyear Meeting 2001.

23. Sturek JK. Point-of-service computer system and drug use evaluation: implications for pharmacy practice in ambulatory care. Am J Hosp Pharm 1989; 46: S17-S20.

24. Felkey BG, Poikonen J. Technology and automation update. J Managed Care Pharm 1998; 4: 345-50.

25. Council on Competitiveness. Highway to health: transforming U. S. health care in the information age. Washington, DC: Author, 1996.

26. Schafermeyer KW. Basics of managed care claims processing: from claims payment to outcomes management. J Managed Care Pharm 1995; 1: 200-205.

27. Dansky KH, et al. Electronic medical records: are physicians ready? J Health Manag 1999; 44: 440-54.

28. Dworkin LA, et al. Experience using radio frequency laptops to access the electronic medical record in exam rooms. Proceedings AMIA Symposium 